\title{
CORRESPONDENCE
}

\section{Vertical transmission of SARS-CoV-2 from infected pregnant mother to the neonate detected by cord blood real-time polymerase chain reaction (RT-PCR)}

Pediatric Research (2021) 89:1592-1593; https://doi.org/10.1038/s41390020-01193-9

\section{INTRODUCTION}

The emergence in December 2019 in Wuhan, China of the novel coronavirus SARS-CoV-2 (the virus that causes COVID-19) caused a pandemic with deadly consequences globally. ${ }^{1,2}$ Viral infections occurring during pregnancy tend to cause complications in mothers and newborns. However, the effects of COVID-19 during pregnancy and possibility of mother-to-child transmission via the transplacental route have not been well documented and remain inconclusive. ${ }^{3}$ Reports have emerged in China of suspected vertical infection based on high levels of $\operatorname{lgM}$ antibodies in the blood of newborns after birth but without viral isolation. ${ }^{4,5}$ Due to the importance of the topic, we report the first newborn in whom SARS-CoV-2 was isolated from umbilical cord blood and two samples of a skin swab by real-time polymerase chain reaction (RT-PCR) immediately after birth, suggesting the occurrence of vertical transmission.

\section{METHODS}

A mother diagnosed with COVID-19 eight days before delivery and her newborn were evaluated for the presence of SARS-CoV-2 in umbilical cord blood and on the skin surface immediately after birth using RT-PCR.

\section{RESULTS}

A 32-year-old G2P1 with gestational diabetes and a diagnosis of SARS-CoV-2 infection progressed to premature labor with no apparent cause at 34 0/7 weeks of gestation. The date of maternal exposure is unknown, but the first symptoms (anosmia, ageusia, runny nose, dry cough, headache and myalgia-without fever) started on April 24, 2020. On April 26, 2020 and the day of delivery, two swab samples for SARS-CoV-2 (nasal and oropharyngeal) by RT-PCR were positive. The mother remained at home with mild symptoms until the beginning of preterm labor, 10 days after the beginning of symptoms on May 4, 2020. Rupture of the membranes occurred during the expulsion period. A male child was born weighing $2130 \mathrm{~g}$ with a strong cry, without delayed cord clamping or skin-to-skin contact. Samples for SARS-CoV-2 investigation collected from the umbilical cord blood and skin swabs (axillary and anterior chest areas) by RT-PCR immediately after birth were all positive. The institutional protocol for cord blood sampling from patients diagnosed with SARS-CoV-2 infection includes a specially trained nurse using complete personal protective equipment. After the placenta is removed by the obstetrician, the nurse receives it in sterile fields and, using sterile material (gloves, syringe and needle), the umbilical vein is wiped with an antiseptic and a needle is inserted into the vein to withdraw the blood sample. Due to oxygen saturation $<70 \%$ and tachydyspnea, nasal CPAP was started during resuscitation and it was necessary to increase the oxygen concentration up to $60 \%$ to reach the target oxygen saturation, after which it was reduced to $25 \%$. Positive pressure ventilation was not performed. The newborn was transported to the neonatal ICU, where antibiotic therapy was started. The chest $\mathrm{X}$-ray was compatible with mild respiratory distress syndrome, diffuse granular opacities but without atypical pulmonary condensation, and progressive improvement of the respiratory condition in the first $24 \mathrm{~h}$. The blood culture was negative, and antibiotic therapy was withdrawn. On the second day of life, a new oropharyngeal swab to investigate SARS-CoV-2 was collected with a negative result. The newborn was tested for IgG and IgM for SARS-CoV-2 on the 4th and 9th days of life, with negative results.

\section{DISCUSSION}

To our knowledge, this is the first report of viral isolation in umbilical cord blood and surface swabs immediately after birth by RT-PCR. Vertical transmission of SARS-CoV-2 was previously suggested by elevated IgM antibodies to SARS-CoV-2 from a child born to a mother with coronavirus disease (COVID-19). ${ }^{4}$ However, a major issue with this technique is the relative inaccuracy of currently available diagnostic tests. Anti-SARS-CoV$2 \mathrm{lgM}$ antibody assays used in perinatal studies from China require further study regarding sensitivity and specificity as well as cross reactivity with nonspecific IgM antibodies. A recent meta-analysis showed that the combination of $\mathrm{lgG} / \mathrm{lgM}$ had a sensitivity of $30.1 \%(95 \% \mathrm{Cl}, 21.4-40.7)$ for $1-7$ days, $72.2 \%$ (95\% Cl, 63.5-79.5) for $8-14$ days, and $91.4 \%(95 \% \mathrm{Cl}, 87.0-94.4)$ for $15-21$ days. ${ }^{6}$ Not all patients infected with SARS-CoV-2 develop specific antibodies to this virus, and the serological response in newborns is a difficult issue to be evaluated. One author detected a positive RT-PCR in a newborn's pharyngeal swab collected $36 \mathrm{~h}$ after birth. ${ }^{7}$ Similarly, three newborns were symptomatic for COVID-19 with positive RTPCR in anal and naso-pharyngeal swabs, two of whom presented with symptoms on the second day of life. ${ }^{8}$ However, the sensitivity of real-time PCR testing is approximately $63 \%$ of infected individuals ${ }^{9}$; therefore, the possibility of contamination after birth cannot be ruled out.

Therefore, definitive evidence is needed to diagnose the vertical transmission of an infected woman with the risk of congenital infection. ${ }^{10}$ Our findings document the vertical transmission of SARS-CoV-2, and we suggest that the routine use of RT-PCR collected at birth from cord blood can be used for parent counseling and to study related perinatal morbidity. 


\section{AUTHOR CONTRIBUTIONS}

C.M.R.-Conception, design, acquisition and analysis of data, drafting the article and final approval of the version to be published. L.P.F., J.R.R.P. and R.d.A.M.Y.-Analysis of data, drafting the article and final approval of the version to be published. G.A.Acquisition and analysis of data, drafting the article and final approval of the version to be published. R.S.B.Z.-Conception, design, acquisition and analysis of data and final approval of the version to be published.

\section{ADDITIONAL INFORMATION}

Competing interests: The authors declare no competing interests.

Consent statement: Patient consent was required and given for the publication of this paper, according to the circular letter (no. 166/18) dated 06/12/18, from the National Commission for Ethics in Research (CONEP), through which it started to demand that studies of the type "Case Report" or "Letter to the Editor" undergo an ethical evaluation via "Plataforma Brasil" (Brazil Plataform) in the CEP/CONEP System, like any other research project.

Publisher's note Springer Nature remains neutral with regard to jurisdictional claims in published maps and institutional affiliations.

Celso M. Rebello (iD)', Linus P. Fascina', Giuliana Annicchino', João R. R. Pinho', Renata de A. M. Yoshida ${ }^{1}$ and

Romy S. B. Zacharias ${ }^{1}$

${ }^{1}$ Hospital Israelita Albert Einstein-Maternal Child Department, Sao

Paulo, SP, Brazil

Correspondence: Celso M. Rebello (celsomr@einstein.br)

\section{REFERENCES}

1. Zhu, N. et al. A novel coronavirus from patients with pneumonia in China, 2019. N. Engl. J. Med. https://doi.org/10.1056/NEJMoa2001017 (2020).

2. The Washington Times. World Health Organization declares COVID-19 outbreak a pandemic. https://www.washingtontimes.com/news/2020/mar/11/world-healthorganization-declares-covid-19-outbre/ (11 March 2020).

3. Society for Maternal Fetal Medicine. Coronavirus (COVID-19) and pregnancy: what maternal-fetal medicine subspecialists need to know. https://s3.amazonaws. com/cdn.smfm.org/media/2322/COVID19-What_MFMs_need_to_know_revision_ 4-11-20_(final)_highlighted_changes._PDF.pdf (2020).

4. Dong, L. et al. Possible vertical transmission of SARS-CoV-2 from an infected mother to her newborn. JAMA https://doi.org/10.1001/jama.2020.4621 (2020).

5. Zeng, $\mathrm{H}$. et al. Antibodies in infants born to mothers with COVID-19 pneumonia. JAMA https://doi.org/10.1001/jama.2020.4861 (2020).

6. Deeks, J. J. et al. Antibody tests for identification of current and past infection with SARS-CoV-2. Cochrane Database Syst. Rev. 6, CD013652 (2020).

7. Wang, S. et al. A case report of neonatal COVID-19 infection in China Clin. Infect. Dis. https://doi.org/10.1093/cid/ciaa225 (2020).

8. Zeng, L. et al. Neonatal early-onset infection with SARS-CoV-2 in 33 neonates born to mothers with COVID-19 in Wuhan, China. JAMA Pediatr. https://doi.org/ 10.1001/jamapediatrics.2020.0878 (2020).

9. Wang, W. et al. Detection of SARS-CoV-2 in different types of clinical specimens. JAMA 323, 1843-1844 (2020).

10. Kimberlin, D. W. \& Stagno, S. Can SARS-CoV-2 infection be acquired in utero? More definitive evidence is needed. JAMA 323, 1788-1789 (2020). 